Collection: Cost Action E29 Meeting 2008 - Istanbul (Turkey)

Future Monitoring and Research Needs for Forest Ecosystems

Guest Editor: Marcus Schaub (WSL, Birmensdorf, CH)

\section{Ozone flux modelling for risk assessment: status and research needs}

\section{Tuovinen J-P}

In this paper, some shortcomings involved in the modelling of ozone fluxes in the context of local-scale risk assessment are discussed, especially as related to the data collected within the International Co-operative Programme on Assessment and Monitoring of Air Pollution Effects on Forests (ICP Forests). An enhanced monitoring strategy, that would provide a sounder basis for the development, validation and application of risk assessment modelling tools, is also suggested.

\section{Keywords: Ozone, Dose, Stomatal flux, Forests, Monitoring}

\section{Introduction}

In Europe, the development of air pollution abatement strategies is founded on the effects-based approach, which includes the ozone-induced plant injury as one of the key effects to be minimized. Within this framework, the risk of ozone damage to vegetation is related to numerical exposure and dose indices (UNECE 2004b, Simpson et al. 2007 , Tuovinen et al. 2007). Both types of index are presently defined within the risk assessment methodology adopted within the Convention of Long-range Transboundary Air Pollution of the United Nations Economic Commission for Europe (UNECE 2004b). However, there is increasing evidence for the superior biological basis of the dose approach (Matyssek et al. 2007).

The exposure and dose indices differ in that exposure can be evaluated from ozone concentration data alone, while for the calculation of ozone dose the stomatal uptake by vegetation must be modelled. In this paper, we will discuss some shortcomings involved in the modelling of ozone fluxes in the context of local-scale risk assessment, especially

Finnish Meteorological Institute, Climate Change Research, P.O. Box 503, Fl-00101 Helsinki, Finland

@) Juha-Pekka Tuovinen (juhapekka.tuovinen@fmi.fi)

Received: Mar 13, 2008 - Accepted: Dec 09, 2008

Citation: Tuovinen J-P, 2009. Ozone flux modelling for risk assessment: status and research needs. iForest 2: 34-37 [online: 2009-01-23] URL:

http://www.sisef.it/iforest/show.php? id $=485$ as related to the data collected within the International Co-operative Programme on Assessment and Monitoring of Air Pollution Effects on Forests (ICP Forests - UNECE monitoring strategy that would provide a sounder basis for the development, validation and application of risk assessment modelling tools.

\section{Flux modelling principles}

The dose-based ozone risk indicator $\left(A F_{\mathrm{st}} Y\right.$, Accumulated stomatal Flux above a threshold $Y$ ) introduced within the UNECE risk assessment methodology (UNECE 2004b) can be written as (eqn. 1):

$$
A F_{s t} Y=\sum_{i=1}^{N} \max \left(F_{s t, i}-Y, 0\right) \cdot \Delta t
$$

where $F_{\text {st }}$ is the stomatal ozone flux per projected leaf area (PLA) to sunlit leaves at the canopy top and $Y$ is the threshold stomatal flux per PLA (in nmol m $\mathrm{m}^{-2} \mathrm{~s}^{-1}$ ). $A F_{\text {st }} Y$ is calculated from hourly values of $F_{\text {st }}$ (denoted by hours to be included in the calculation period, which corresponds to the growing season. The stomatal flux in eqn. (1) is defined as (eqn. 2):

$$
F_{s t, i}=c_{i}\left(h_{v e g}\right) \hat{g}_{s t, i}\left(h_{v e g}\right)
$$

where $c_{\mathrm{i}}$ is the hourly ozone concentration, $h_{\text {veg }}$ is vegetation height and $\hat{g}_{\mathrm{st}, \mathrm{i}}$ is the effective stomatal conductance (here referred to as "effective" because it also depends on the conductances of the leaf boundary layer and the external plant surfaces, see Tuovinen et elled using the $\mathrm{DO}_{3} \mathrm{SE}$ (Deposition of Ozone and Stomatal Exchange) model, which is based on a multiplicative plant species-spe2007). We will also suggest an enhanced $i)$, so $\Delta t=1 \mathrm{~h} ; N$ denotes the number of al. 2007). The stomatal conductance is mod- cific parametrization representing the stomatal responses to environmental and phenological factors (Emberson et al. 2000, UNECE 2004b). Thus the stomatal flux depends on two components, a concentration and a stomatal conductance, both of which are equally significant for the flux.

\section{Measuring concentration}

As indicated by eqns. (1) and (2), the stomatal flux for $A F_{\text {st }} Y$ is, by definition, to be calculated from hourly-averaged ozone concentration data. These data could be obtained from a standard ozone analyser that is based on UV absorption photometry; this is the reference method defined in the EU Directive on ambient ozone (EU 2002). Within ICP Forests, passive sampling is defined as an option for concentration measurements (UNECE 2000) and, being relatively inexpensive and easy to deploy in the field, is widely used at the ICP Forests Level II monitoring plots across Europe (UNECE 2007). A comparison of passive samplers against the reference method at some ICP Forests sites demonstrated the feasibility of this method but also showed the associated methodological uncertainty (Sanz et al. 2007).

A fundamental property of passive sampling is the time-averaging of the measurement. As a typical sampling time for ozone is two weeks (UNECE 2000), the concentration data obtained have a low temporal resolution as compared to the definition of many air quality indicators, and especially so for $A F_{\text {st }} Y$. Thus the hourly data must be derived from the measured mean (14-d or so) concentration by using a statistical technique with additional meteorological (Krupa et al. 2003) or topographical (Loibl et al. 1994) data. This requires a significant amount of prior (hourly) calibration data, and unavoidably further uncertainty is introduced in the modelled hourly values, as exemplified by the results of Gerosa et al. (2007). Moreover, it is questionable to what extent the correlation between high ozone concentrations and environmental factors limiting stomatal uptake, which was a major motivation for the flux-based approach in the first place, can be simulated by this approach.

According to the monitoring recommendations of ICP Forests, the passive samplers are to be located in an open field near, but outside, the forest at a 2-4-m height (UNECE 2000). This contrasts the definition of stomatal flux (eqn. 2), which should be calculated using the tree-top concentration (at $h_{\text {veg }} \sim 20 \mathrm{~m}$ ). Consequently, the measured concentration must be transformed to the correct reference height (Fig. 1). This can be accomplished by using a flux-gradient model that relates the vertical concentration profile to wind speed, surface roughness and the 


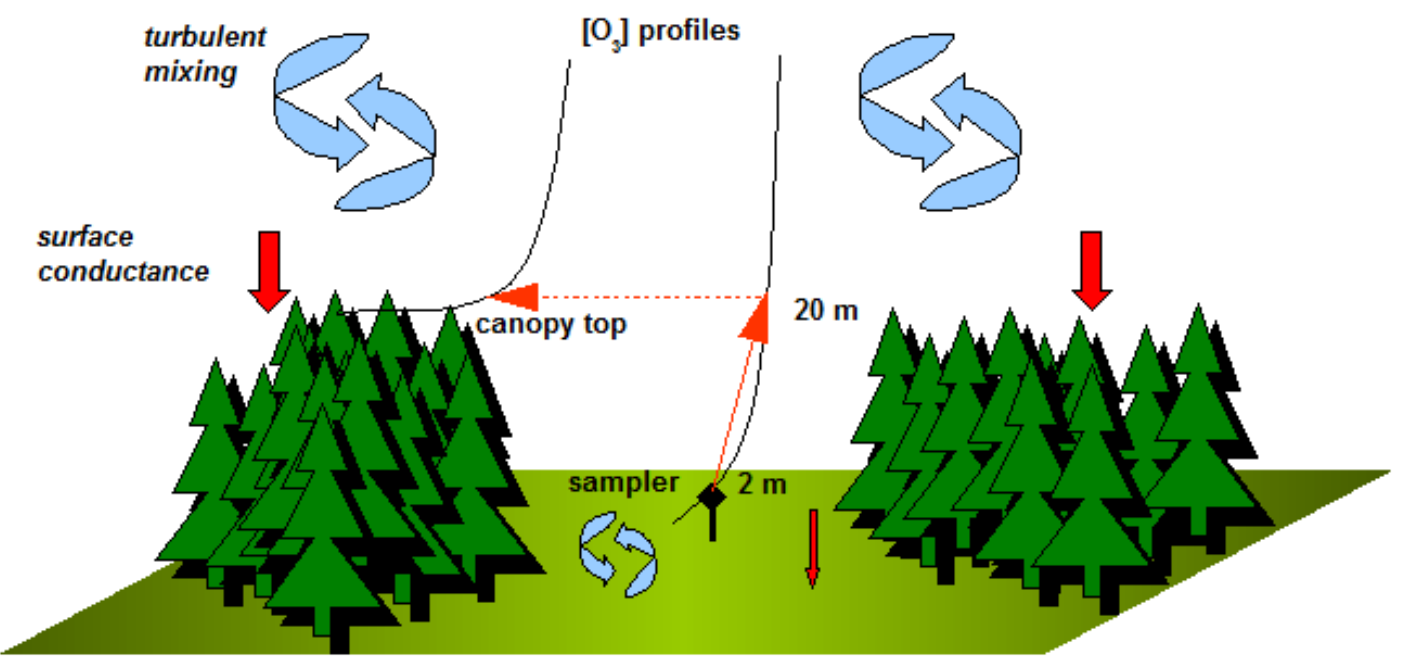

Fig. 1 - Schematic presentation of the height transformation for estimating the canopy-top concentration.

Fig. 2 - The flux measurement network of the CarboEurope project (CarboEurope 2004).

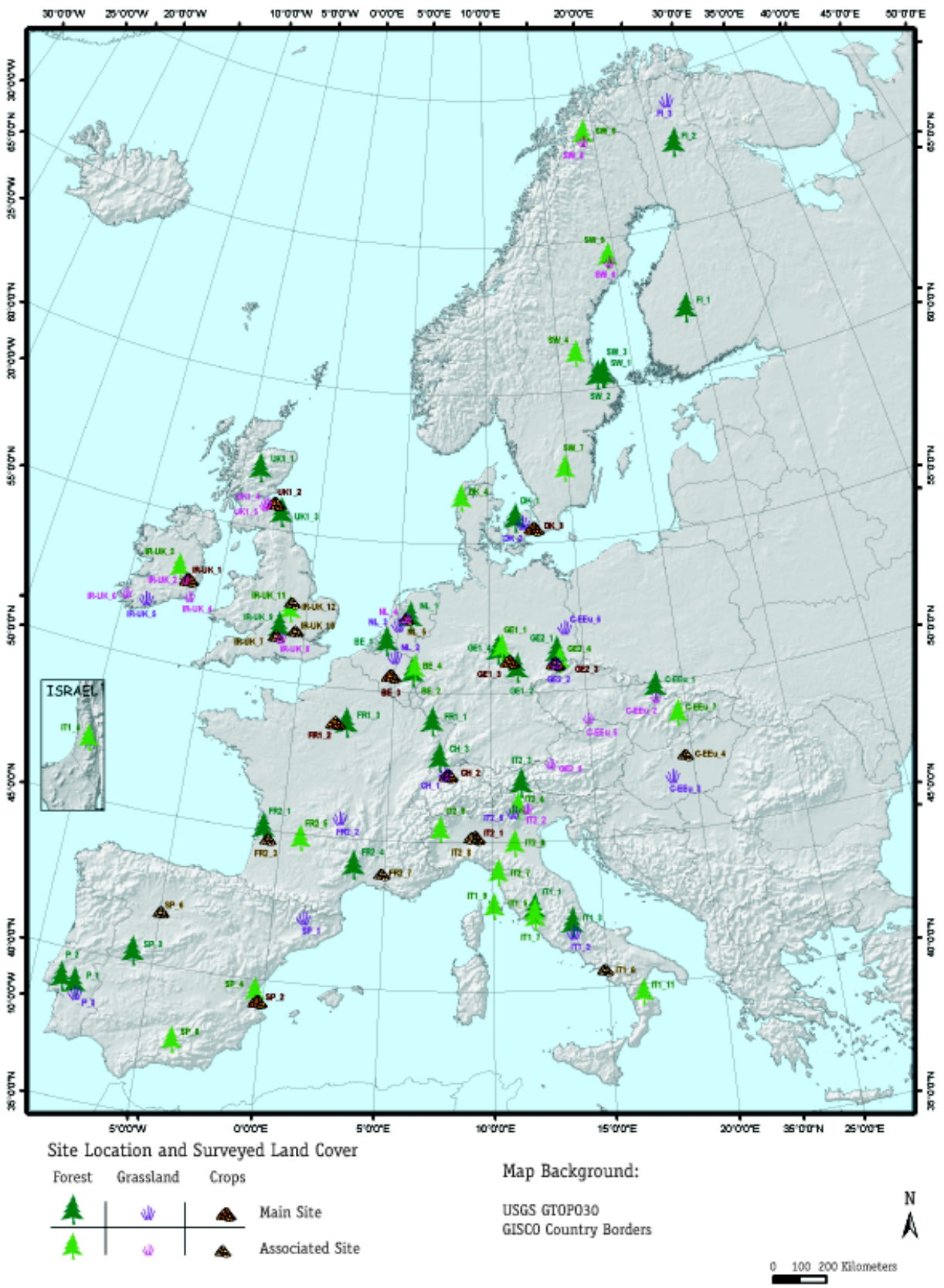


bulk surface conductance of ozone deposition (UNECE 2004b). In principle, this kind of model is founded on a micrometeorological theory which assumes horizontal homogeneity. However, this assumption is not fulfilled very well within the present experimental configuration. Furthermore, neutra atmospheric stability, constant surface conductance and independence of the 20-m concentration of the underlying vegetation were employed as necessary assumptions by Schaub et al. (2007), who modelled ozone doses using the ICP Forests monitoring data.

\section{Modelling stomatal conductance}

The modelling of stomatal conductance with $\mathrm{DO}_{3} \mathrm{SE}$ depends on data on wind speed, photosynthetically active radiation, air temperature and air humidity at $h_{\mathrm{veg}}$, and data on soil moisture (Emberson et al. 2000, UNECE 2004b). According to UNECE (2004a), the recommended height for wind measurements is $10 \mathrm{~m}$, while for most of the other meteorological variables it is $2 \mathrm{~m}$. This means that the measured data should be transformed to $h_{\text {veg }}$, using a micrometeorological flux-gradient relationship similar to that employed for the vertical concentration profile. In addition, since soil moisture status is not measured at the ICP Forests monitoring plots, it needs to be modelled based on water budget principles when applying the $\mathrm{DO}_{3} \mathrm{SE}$ model (Schaub et al. 2007).

A general problem related to flux modelling is the limited validation of models, and here we can note several issues. Firstly, in many cases there are little independent data available for statistically sound cross-validation. This results in conceptual problems concerning the distinction between model calibration and validation, as is evident from the evaluations of the canopy-scale version of $\mathrm{DO}_{3} \mathrm{SE}$ (Tuovinen et al. 2004).

Secondly, field experiments are seldom designed from the point of view of the characteristics of a certain model, so the data provided by these efforts may be far from optimal for model validation. For example, the observational data may not cover a full range of environmental conditions, as encountered when running the model for a complete growing season, or all the necessary input data, such as soil moisture, are not measured at all (Tuovinen et al. 2004). In particular, the partitioning between stomatal and non-stomatal fluxes would be essential for evaluating flux models. At the canopy scale, this would require measurements of water vapour exchange and/or xylem sap flow. Finally, air quality monitoring programmes, such as that run at the ICP Forests Level II monitoring plots, provide little support for the validation of flux models, as the ozone (or water vapour) flux is not measured.

\section{Discussion}

While the passive sampling technique for measuring ozone concentrations offers many advantages over continuous monitoring, especially in a remote and complex forest environment, we have here identified several uncertainty sources specific to the application of this technique to the modelling of ozone fluxes. Some of these issues arise from the monitoring recommendations provided by ICP Forests. All the concentration-related uncertainties discussed above would be avoided, if the ozone concentration was measured at the canopy top using a UV absorption analyser providing hourly-resolved data. In addition, the location of meteorological sensors is not ideal for flux modelling.

In general terms, it can be argued that we are dealing with a trade-off situation as regards the ozone monitoring strategy. On the one hand we have the inexpensive alternative relying on passive sampling; on the other, we could replace this by the costly continuous monitors. The inexpensive alternative makes it possible to run an extensive measurement network. In this case, however, the application of flux-based risk indicators, which should gradually replace the concentration-based indices, entails a large number of additional calculation steps with associated simplifying assumptions. The overall uncertainty involved in these simplifications remains to be quantified. The alternative based on continuous monitors is too costly to be implemented across the existing ICP Forests network. In addition, measurements of ozone deposition fluxes would be needed for model development and validation.

In order to avoid the straightforward tradeoff outlined above, an alternative approach could be adopted. We suggest establishing, in addition to the existing Level II sites, a small number of well-equipped measurement sites, "supersites" or "Level III sites", that would provide data specifically for the fluxbased risk assessment purposes. For the calculation of $F_{\text {st }}$ and $A F_{\text {st }} Y$, the canopy-top ozone concentration (possibly with vertical within-canopy profiles) and all the input data needed for $\mathrm{DO}_{3} \mathrm{SE}$ would be measured at these sites on an hourly basis. For further development and validation of $\mathrm{DO}_{3} \mathrm{SE}$ and other flux models, ozone and water vapour fluxes would be measured above the canopy using the micrometeorological eddy covariance technique, possibly enhanced by sap flow and shoot-scale gas exchange measurements. To overcome the financial and logistic restrictions, all this could be accomplished in practice by collaborating with the existing flux measurement stations ("flux towers") run across Europe, mainly within large-scale projects such as CarboEurope (2004) and NitroEurope (2006) (Fig. 2). These stations constitute a potential framework for the su- persites, providing the necessary infrastructure and expertise, extensive measurement programmes and data bases, as well as a direct connection to flourishing research on atmosphere-biosphere exchanges (e.g., Piao et al. 2008)

\section{Acknowledgements}

Discussions with Lisa Emberson (SEIYork), Dave Simpson (EMEP MSC-W) and Mika Aurela (FMI) are highly appreciated.

\section{References}

CarboEurope (2004). CarboEurope-IP, Assessment of the European Terrestrial Carbon Balance, Integrated Project, Strategic Plan 20042008. Max-Planck-Institute for Biogeochemistry, Jena, Germany, pp. 28. [online] URL: http://www.carboeurope.org

Emberson LD, Ashmore MR, Cambridge HM, Simpson D, Tuovinen J-P (2000). Modelling stomatal ozone flux across Europe. Environmental Pollution 109: 403-413. - doi: 10.1016/S02697491(00)00043-9

EU (2002). Directive 2002/3/EC of the European Parliament and the Council of 12 February 2002 relating to ozone in ambient air. Official Journal of European Communities L 67: 14-30.

Gerosa G, Ferretti M, Bussotti F, Rocchini D (2007). Estimates of ozone AOT40 from passive sampling in forest sites in South-Western Europe. Environmental Pollution 145: 629-635. doi: 10.1016/j.envpol.2006.02.030

Krupa S, Nosal M, Ferdinand JA, Stevenson RE, Skelly JM (2003). A multi-variate statistical model integrating passive sampler and meteorology data to predict the frequency distributions of hourly ambient ozone $\left(\mathrm{O}_{3}\right)$ concentrations. Environmental Pollution 124: 173-178. - doi: 10.1016/ S0269-7491(02)00407-4

Loibl W, Winiwarter W, Kopsca A, Zueger J, Baumann R (1994). Estimating the spatial distribution of ozone concentrations in complex terrain. Atmospheric Environment 28: 2557-2566. doi: 10.1016/1352-2310(94)90430-8

Matyssek R, Bytnerowicz A, Karlsson P-E, Paoletti E, Sanz M, Schaub M, Wieser G (2007). Promoting the $\mathrm{O}_{3}$ flux concept for European forests. Environmental Pollution 146: 587-607. doi: 10.1016/j.envpol.2006.11.011

NitroEurope (2006). NitroEurope IP brochure. Centre for Ecology and Hydrology, Edinburgh, UK. [online] URL: http://www.nitroeurope.eu Piao S, Ciais P, Friedlingstein P, Peylin P, Reichstein M, Luyssaert S, Margolis H, Fang J, Barr A, Chen A, Grelle A, Hollinger DY, Laurila T, Lindroth A, Richardson AD, Vesala T (2008). Net carbon dioxide losses of northern ecosystems in response to autumn warming. Nature 451: 4952. - doi: 10.1038/nature06444

Sanz MJ, Calatayud V, Sánchez-Peña G (2007). Measures of ozone concentrations using passive sampling in forests of South Western Europe. Environmental Pollution 145: 620-628. - doi: 10.1016/j.envpol.2006.02.031

Schaub M, Emberson L, Büker P, Kräuchi N 
(2007). Preliminary results of modeled ozone uptake for Fagus sylvatica L. trees at selected EU/ UN-ECE intensive monitoring plots. Environmental Pollution 145: 636-643. - doi: 10.1016/j.envpol.2006.02.029

Simpson D, Ashmore M, Emberson L, Tuovinen J-P (2007). A comparison of two different approaches for mapping potential ozone damage to vegetation. A model study. Environmental Pollution 146: 715-725. - doi: 10.1016/j.envpol.2006.04.013

Tuovinen J-P, Ashmore M, Emberson L, Simpson D (2004). Testing and improving the EMEP ozone deposition module. Atmospheric Environment 38: 2373-2385. - doi: 10.1016/ j.atmosenv.2004.01.026

Tuovinen J-P, Simpson D, Emberson L, Ashmore M, Gerosa G (2007). Robustness of modelled ozone exposures and doses. Environmental Pollution 146: 578-586. - doi: 10.1016/- j.envpol.2006.03.011

UNECE (2000). Manual on methods and criteria for harmonized sampling, assessment, monitoring and analysis of the effects of air pollution on forests. Part X: Monitoring of air quality. International Co-operative Programme on Assessment and Monitoring of Air Pollution Effects on Forests, United Nations Economic Commission for Europe (UNECE) Convention on Long-range Transboundary Air Pollution, Geneva, Switzerland, pp. 20. [online] URL: http://www.icpforests.org/Manual.htm

UNECE (2004a). Manual on methods and criteria for harmonized sampling, assessment, monitoring and analysis of the effects of air pollution on forests. Part VII: Meteorological Measurements. International Co-operative Programme on Assessment and Monitoring of Air Pollution Effects on Forests, United Nations Economic Commission for Europe (UNECE) Convention on Long- range Transboundary Air Pollution, Geneva, Switzerland, pp. 40. [online] URL: http://www.icp-forests.org/Manual.htm

UNECE (2004b). Mapping critical levels for vegetation. Manual on methodologies and criteria for modelling and mapping critical loads and levels and air pollution effects, risks and trends. United Nations Economic Commission for Europe (UNECE) Convention on Long-range Transboundary Air Pollution, Geneva, Switzerland, pp. 254. [online] URL: http://www.icpmapping.org

UNECE (2007). The condition of forests in Europe, 2007 executive report. United Nations Economic Commission for Europe (UNECE) Convention on Long-range Transboundary Air Pollution, Geneva, Switzerland, pp. 34. [online] URL: http://www.icp-forests.org/RepTech.htm 